\title{
Improvement of sediment transport by excavation of causeway in Funafuti Atoll, Tuvalu
}

Sato, D. ${ }^{1)}, H_{.}$, Yokoki $^{1)}$, and H., Kayanne ${ }^{2)}$

1) Dept. of Urban and Civil Engineering, Ibaraki University, Japan

2) Dept. of Earth and Planetary Science, The University of Tokyo, Japan

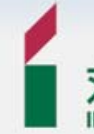

茨城大学 Ibaraki University

\section{Introduction} width of $19 \mathrm{~km}$ and north-south width of 25 km (Fig. 1(a)). Fongafale Islet in the eastern part of Funafuti Atoll has high population density (Fig. 1(b)). The sediment production from reef-living organisms such as corals and foraminifers is considered to be decreasing recently due to human impact and this decrease causes erosion. On the sustainable plan of island conservation, the natural process of sediment production and transportation should be used effectively (Fig. 2). This study focused on the improvement of sediment transport by excavation of the causeway located in the northern part of Fongafale Islet, in order to increase the lagoonal sediment transport Then, accretion due to excavation was evaluated numerically.
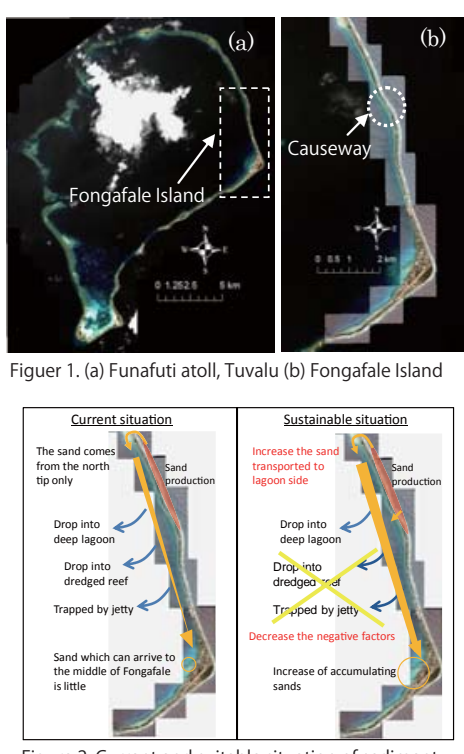

Figure 2. Current and suitable situation of sedimen transport in Fongafale Island
Calculation method

Numerical calculation of wave field and sediment transport was carried out in this study. The wave field in Funafuti Atoll was calculated by SWAN model (Booij et al, 1999). In the calculation of sediment transport, the local sediment transport rate constructed by Sato and Kabiling (1994) was adopted to calculate the sediment transport on reef-flat. Reappearance of wave phase was calculated using the cnoidal wave of the finite amplitude wave theory. Calculation domains are indicated in Fig 3. There are four nesting domains. Wave field and sediment transport were calculated by all domains and domain 2 and 4, respectively. Boundary conditions of monthly-averaged wind and wave were calculated by ECMWF re-analysis data and observed data. Sediment production area is indicated in domain 4 of Fig. 3, which was set based on field investigation. Sediment transport was calculated every day. Calculation of wave field was iterated every three days. Sediment production rate by foraminifers was determined by $0.02 \mathrm{~m}^{3} / \mathrm{m}^{2} /$ year that was estimated from field survey.

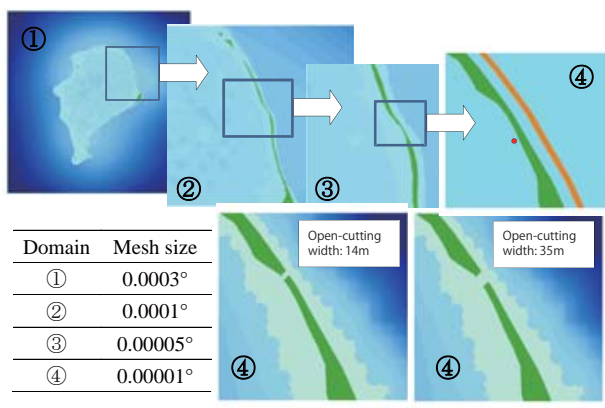

Figure 3. Calculation domain and image of the open cutting of causeway

\section{Effective width of excavation}

Five cases of different width of excavation $(7,14,28,35,62,120 \mathrm{~m})$ were examined by using the constructed numerical model. Figure 4 shows that the deposited sand in the different excavation width of $7,28,120 \mathrm{~m}$, respectively. The green colored areas shows the island. When the open-cutting width is narrow $(7 \mathrm{~m})$, the sand supplied on the ocean-side reef-flat was not distributed in the lagoon-side reef-flat widely. Increasing of the open-cutting width accelerated the inflow sediment transport from ocean to lagoon-side.

Figure $\mathbf{5}$ indicated the longshore sediment transport rate at the red circle in Fig. 3 in each open-cutting width. The longshore sediment transport rate is in proportion to the open-cutting width until $28 \mathrm{~m}$ of the open-cutting width of the causeway. In that case, the sediment volume of both transport from ocean to lagoon and transport along the lagoonal coast was increased uniformly. However, the sediment transport rate between $28 \mathrm{~m}$ and $120 \mathrm{~m}$ was changed to the inverse proportion. Thus, even if the open-cutting width of the causeway was expanded over $28 \mathrm{~m}$ for increasing the sediment transport from ocean to lagoon, it does not contribute to increase the longshore sediment transport in lagoonal coast because the sediment flushed out to the deep lagoon. This numerical examination identified that the efficient width of the open-cutting of the causeway is about $30 \mathrm{~m}$. Therefore, post-calculation was conducted using the topographic data with the Figu open-cut width as $28 \mathrm{~m}$.

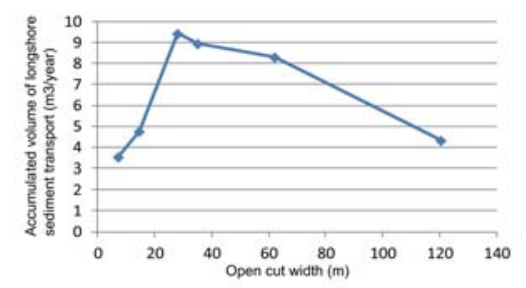
width
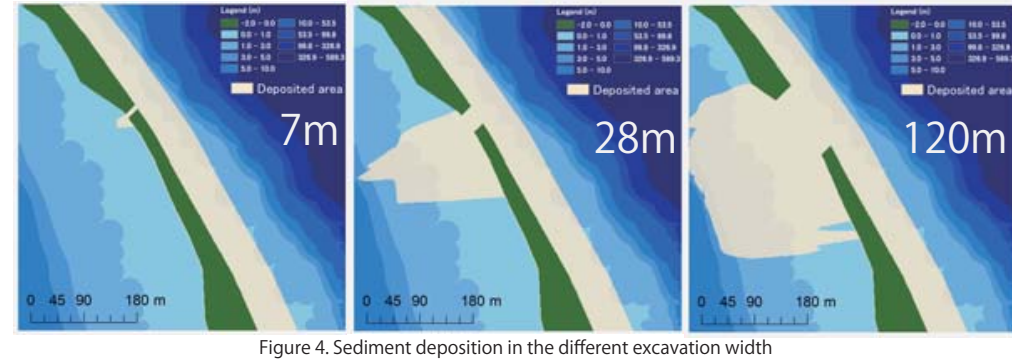

Figure 4. Sediment deposition in the different excavation width

Effectiveness of accumulation Figure 6 shows the accreted sand in the middle part of Fongafale island in 5 years later. It is indicated that the sediment transportation along lagoonal coast was toward southward. It was also identified that the excavation of the causeway contributed to accelerating of accretion in the lagoonal beach in Fongafale island. In order to implement the sustainable morphological conservation using the natural process of island morphological changes, the excavation of the causeway is a desirable method for effective use of supplied sediments.

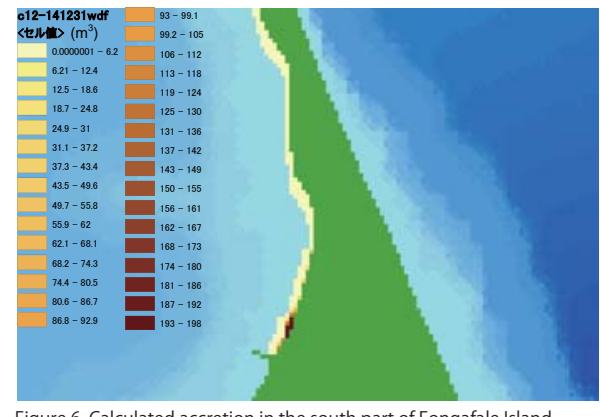

Figure 6. Calculated accretion in the south part of Fongafale Island
Conclusion Consideration of effective excavation width indicated that the most desirable width is around $30 \mathrm{~m}$. Even if the excavation width is increased more than $30 \mathrm{~m}$, the longshore sediment transport didn't increase. Excavation of the causeway increased lagoonal sediment transportation and it accelerated lagoonal accumulation. Calculated results indicated that the excavation of causeway is effective for improvement of longshore sediment transport, and it connects to sustainable conservation of lagoonal coast in Fongafale Islet.
Acknowledgement This study was supported by Science and Technology Research Partnership for Sustainable Development (SATREPS). The authors considerably appreciate it.
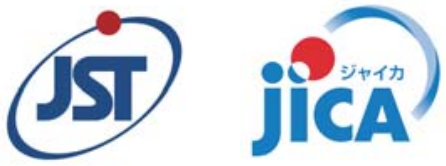